\title{
ARTICLE OPEN \\ Oral health knowledge, attitude and behaviour of dental students in a private university
}

\author{
Azhar Abdulrahman Al-wesabi ${ }^{1}$, Fatma Abdelgawad ${ }^{1}$, Hisako Sasahara ${ }^{2}$ and Kamal El Motayam ${ }^{1}$
}

INTRODUCTION: The positive attitude and behaviour of dental students can be improved during their undergraduate studies and is considered an essential factor in promoting the oral self-care habits of their patients and society in general.

AIM: This study was conducted to evaluate the oral health knowledge, attitudes and behaviours among undergraduate dental students at a private university, based on the year of undergraduate studies.

MATERIAL AND METHODS: A self-administered questionnaire based on the Hiroshima University-Dental Behavioural Inventory was distributed among 783 undergraduate dental students from 1st to 5th year. Statistical analysis was performed using SPSS version 20. The Mann-Whitney $U$ test and one-way ANOVA tests (Kruskal-Wallis test) were used.

RESULTS: The scores of oral health knowledge, attitude and behaviour between preclinical and clinical dental students were found to have statistically significant differences $(P<0.001)$. The variation of knowledge, attitude and behaviour scores from $1 \mathrm{st}$ to 5 th year undergraduate studies was shown to be statistically significant with the year of study $(P<0.001)$. The study showed significant improvement in the knowledge, attitude and behaviour of the final year dental students as compared with the 1st year dental students.

CONCLUSION: Preclinical students need properly designed oral health educational programs to increase their attitude and behaviour toward oral health.

BDJ Open (2019)5:16 ; https://doi.org/10.1038/s41405-019-0024-x

\section{INTRODUCTION}

Attitude is defined as 'the way in which a person views and evaluates something or someone. Attitudes determine whether people like or dislike things and therefore how they behave towards them'. ${ }^{1}$ Dental students are expected to play a critical role in instructing public oral health; their attitude reflects their understanding of the importance of disease prevention and their responsibility for improving their patients' oral health. ${ }^{2}$ Therefore, the level of their own oral health behaviour can serve as positive models for their patients, families and friends. ${ }^{3}$

The Hiroshima University-Dental Behavioural Inventory (HU-DBI) questionnaire revealed interesting facts regarding differences in dental health attitude and behaviour among undergraduate dental students. So, it may pave the way for developing new programs aimed at improving dental students' attitude and behaviour. Thus, the dental universities could assess their curricula to encourage needful oral health practices and positive behavioural attitudes. Thus, allowing them to modify their curricula at all levels of dental education. ${ }^{4}$

Many studies used the questionnaire to assess gender differences in oral health behaviours ${ }^{5-7}$ and variations between the cultures. ${ }^{8,9}$ Furthermore, Cortes et al. ${ }^{10}$ showed that oral health behaviour and attitudes improve with educational level.

Changing and modifying the dental curriculum will provide dental students with the knowledge, attitude and behaviour needed. This could also affect their oral self-care habits as well as increase their responsibility to motivate good oral health habits in their patients. ${ }^{11-13}$

There is limited data regarding the attitude and behaviour of dental students in Egypt. Hence, the purpose of this study is to assess the oral health knowledge, attitude and behaviour to answer our research question which is the difference of oral health knowledge, attitude and behaviour among undergraduate dental students from all levels.

\section{MATERIALS AND METHODS}

Study setting and participants

This cross-sectional study of oral health knowledge, attitude and behaviour of dental students in a dental school at a private University was carried out in the academic year 2015-2016 after approval from the Dental Research Ethics Committee of Faculty of Dentistry, Cairo University. A convenience consecutive sampling technique was employed to select dental students from 1st to 5 th level who were invited to complete the questionnaire after their lectures. Only those students agreeing to participate in the study were considered. Arabic and English self-administered questionnaire, consisting of 20 items in a dichotomous response based on HU-DBI ${ }^{14}$ was distributed among 783 students. Preclinical students were included from 1st, 2nd and 3rd years. While, clinical students were included from 4th to 5 th year.

To limit information bias, they were provided with a full explanation concerning the nature of the study, allowed to

\footnotetext{
${ }^{1}$ Paediatric Dentistry and Dental Public Health Department, Faculty of Dentistry, Cairo University, 11 El-Saraya Street, El Manial, Cairo, Egypt and ${ }^{2}$ Integrated Health, Institute of Biomedical and Health Sciences Hiroshima University, Hiroshima, Japan

Correspondence: Azhar Abdulrahman Al-wesabi (azhar-ali@dentistry.cu.edu.eg)
} 
interact with the researcher for understanding the questions without leading their answers and asked to write exactly what they feel, conduct and perform to provide us with the best of their knowledge.

\section{Questionnaire}

The questionnaire was designed to record self-reported oral health (knowledge) (items no: 2,8,10,15,19), oral health attitude (items No: 6,11,14) and oral hygiene behaviour (items no: $4,9,12,16)$.

Items $4,9,11,12,16$ and 19 are given 1 point if the respondent agrees. Also, Items 2, 6, 8, 10, 14 and 15 are given 1 point if the respondent disagrees. Hence, the maximum possible score is out of 12 and the minimum score is 0 . The higher the score means the better the oral health attitude and behaviour for each student. HUDBI questionnaire included eight dummy items which are not included in the final scoring system. ${ }^{15}$

\section{Statistical analysis}

The statistical analysis was performed using the software SPSS version 20. The difference of the oral health knowledge, attitude and behaviour between preclinical and clinical students was assessed by Mann-Whitney $U$ test. The variation of the scores from 1st to 5th year students of each of knowledge, attitude and behaviour was analysed using Kruskal-Wallis test. $P \leq 0.05$ was considered significant.

\section{RESULTS}

A total of 783 dental students, the HU-DBI inventory were completed by 780 students of which 372 were males and 408 were females. The participation was highest in the 1st year (179) and lowest in the 5 th year (136) as shown in Table 1. The overall mean HU-DBI score was $6.77 \pm 1.73$.

The percentages of "agree" responses to the 12 items of the HU$\mathrm{DBI}$ questionnaire were presented in Table 2. Bleeding gums (item-2) were reported in $29.8 \%$ of the participants; $60.1 \%$ answered that it was impossible to prevent gum disease with only tooth brushing (item-14); and $56.1 \%$ reported that they postponed going to the dentist until they had a toothache (item15). In addition, $39.9 \%$ of the students felt that they sometimes took too much time to brush their teeth (item-19). A higher response of "agree" for item-12 ("Checking the teeth in the mirror after brushing"; $82.3 \%$ ), and item-9 ("brush each of my teeth carefully"; 65.6\%) was found, reflecting higher aesthetic awareness among the dental students.

Table 3 reveals the difference between each of the knowledge, attitude and behaviour scores between preclinical and clinical students analysed using Mann-Whitney $U$ test. Clinical students' scores were significantly higher than preclinical ones for knowledge, attitude and behaviour with $P=0.000, P=0.000, P=0.026$, respectively.

Kruskal-Wallis test was carried out to compare the percentage of agree responses scores of knowledge, attitude and behaviour of 1 st -5 th year students. The test showed a statistically significant difference in knowledge, attitudes and behaviours among all levels with $P=0.000, P=0.001, P=0.026$, respectively.

Figure 1(1-3) show a Penta histogram for the knowledge, attitude and behaviour among all five academic levels. In Fig. 1(1), the yellow lines show that there was a statistically significant difference in attitude of students between year 2 and 4 with a $P<$ 0.05 , as well as between level 2 and 5 with a $P<0.01$. In Fig. 1(2) there was a statistically significant difference in behaviour of students between year 2 and 4 with a $p<0.01$.

In Fig. 1(3) the yellow lines show that there was a statistically significant difference in knowledge of students between level 1 and 4 with a $P<0.01$ and level 1 and 5 with a $P<0.01$, as well as there was a statistically significant difference between level 3 and
4 with a $P<0.01$ and level 3 and 5 with a $P<0.01$. While the black lines show no statistical significant difference.

\section{DISCUSSION}

Hiroshima University Dental Behaviour Inventory questionnaire (HU-DBI) is an efficient instrument in identifying differences in oral health behaviours among dental students from different countries due to the difference in the health education systems ${ }^{16}$ and the curriculum dissimilarities of dental universities. ${ }^{8}$ It could be used as a basis for developing additional programs aimed at improving dental students' attitudes and behaviours. The dummy items were included in the original HU-DBI questionnaire to establish a rapport and help in gaining the students participation in the study.

The lowest agree responses reported for bleeding gum (item-2) was in level 5 compared with other levels. This might reflect their awareness towards periodontal disease prevention due to increase in their clinical experience. This finding is in accordance with the percentage of agree responses of level 5 in Patiala, India ${ }^{17}$ and approximately the same in Jordan. ${ }^{18}$

Dental students' awareness about microbial dental plaque was reported in (item-4) if they noticed some white sticky deposits on their teeth. There was a low percentage in agree responses for all levels and it might be due to misinterpretation of this question as whether their teeth were clean or not instead of being aware of plaque. ${ }^{13}$ Also, during our questionnaire distribution, students were asking about the meaning of white sticky deposits.

A lower percentage of clinical students agreed that they "can't help having false teeth when they were old" in (item-6) than preclinical students, this might be explained by fact that as educational level progressed, students become more attentive about their dentition, aware of the limitations and the impact of dentition loss on their dental function and aesthetic. ${ }^{19}$ This percentage is in accordance with that in UAE. ${ }^{20}$

In addition, most of the preclinical students had less oral health knowledge as they thought that their teeth would get worse despite daily brushing (item-8) and they had never been taught professionally how to brush their teeth (item-10). This can be explained by the fact that students had low oral health awareness and poor knowledge when they started their dental education. A possible cause of this is the lack of effective school-based oral health programs at the national level that seek to help children improve and maintain their oral health. ${ }^{11}$ Since the dental students are not receiving this before they enter dental school, oral health programs can be included in the preclinical curriculum to promote oral health awareness and knowledge. The finding of items 8 and 10 is in accordance to that in $\mathrm{UAE}^{20}$ and Britain. ${ }^{9}$

A higher total agree responses for (item-9) "brush each of my teeth carefully" and (item-12) "Checking the teeth in the mirror after brushing" were reported in all academic years, reflecting higher aesthetic awareness among the dental students. This percentage is very close to that in Bangalore, India. ${ }^{21}$

Most of the dental students agreed that it was impossible to prevent gum disease with tooth brushing alone (item-14), because of their belief that the most effective method to prevent dental caries and gum diseases is the teeth brushing, ${ }^{11}$ but there are other methods and techniques with brushing, they may be unaware of. This is similar to the total percentage of agree responses in $\mathrm{UAE}^{20}$

Majority of dental students from all levels reported that they "put off going to the dentist until they have toothache" (item-15), which is similar to frequencies stated among dental students in Japan. ${ }^{22}$ This might be due to the high cost of dental services as well as fear of pain, previous bad dental experiences and the time required for frequent visits in agreement with the study done by Dagli et al. ${ }^{23}$

Regarding the total mean scores in this study, there was poor knowledge, attitude and behaviour among dental students and 
Table 1. Academic levels, number of participants, mean and standard deviation of individual scores



Table 2. HU-DBI questionnaire item, percentage of agree response and level of dental education [agree/(agree + disagree $) \times 100$ ]

\begin{tabular}{|c|c|c|c|c|c|c|}
\hline & $\begin{array}{l}\text { Level } 1 \\
\text { Total }\end{array}$ & $\begin{array}{l}\text { Level } 2 \\
\text { Total }\end{array}$ & $\begin{array}{l}\text { Level } 3 \\
\text { Total }\end{array}$ & $\begin{array}{l}\text { Level } 4 \\
\text { Total }\end{array}$ & $\begin{array}{l}\text { Level } 5 \\
\text { Total }\end{array}$ & Total \\
\hline 2- My gums tend to bleed when I brush my teeth. (D)** & $43.0 \%$ & $27.6 \%$ & $34.4 \%$ & $28.4 \%$ & $11.0 \%$ & $29.8 \%$ \\
\hline 6- I think that I cannot help having false teeth when I am old. (D) & $20.8 \%$ & $15.1 \%$ & $14.3 \%$ & $13.0 \%$ & $6.6 \%$ & $14.3 \%$ \\
\hline $8-1$ think my teeth are getting worse despite my daily brush. (D) & $23.5 \%$ & $21.7 \%$ & $29.6 \%$ & $17.9 \%$ & $19.9 \%$ & $22.5 \%$ \\
\hline 11- I think I can clean my teeth well without using toothpaste. (A) & $19.7 \%$ & $13.2 \%$ & $14.9 \%$ & $30.8 \%$ & $27.9 \%$ & $21.2 \%$ \\
\hline 12-I often check my teeth in a mirror after brushing alone. (A) & $86.4 \%$ & $82.1 \%$ & $77.3 \%$ & $83.5 \%$ & $81.6 \%$ & $82.3 \%$ \\
\hline 14- It is impossible to prevent gum disease with tooth brushing alone. (D) & $55.6 \%$ & $68.4 \%$ & $59.7 \%$ & $58.5 \%$ & $58.8 \%$ & $60.1 \%$ \\
\hline 15- I put off going to the dentist until I have a toothache. (D) & $57.5 \%$ & $58.6 \%$ & $61.0 \%$ & $51.9 \%$ & $50.7 \%$ & $56.1 \%$ \\
\hline 16- I have used a dye to see how clean my teeth are. (A) & $6.7 \%$ & $5.3 \%$ & $3.9 \%$ & $8.2 \%$ & $5.9 \%$ & $6.0 \%$ \\
\hline
\end{tabular}

Table 3. Comparison of the scoring between the preclinical and clinical students

\begin{tabular}{|c|c|c|c|c|c|c|}
\hline & Mean rank & $P$ value & Mean rank & $P$ value & Mean rank & $P$ value \\
\hline Clinical year & 441.03 & & 427.85 & & 411.77 & \\
\hline
\end{tabular}

this might be attributed to that preventive courses, knowledge, experience of dental students gained from their basic dental subjects and training had minor influence on their own oral health attitude and behaviour. This is in accordance to the total mean score in Japan, ${ }^{24}$ India, ${ }^{23}$ Turkey $^{13}$ and Croatia. ${ }^{25}$ This was higher than Chinese, ${ }^{9}$ Sudanese ${ }^{6}$ and Yemeni $^{7}$ dental students, but lower than British ${ }^{9}$ and Japanese students. ${ }^{22}$ This discrepancy may be related to difference in the curriculum of the school, cultural attitude and behaviour.

The comparison of knowledge, attitude and behaviour between preclinical and clinical students revealed that knowledge, attitude and behaviour of clinical students are higher than that of preclinical ones. This could be due to the increasing experience of the clinical students about oral health care being in contact with patients in clinical environment. In addition, as they progress in their dental education, students may become more conscious of their overall health and more attentive to oral health related issues; therefore, they adopt better oral health attitude and behaviour. This finding is in consistence with previous study done in Turkey, Lithuania and India by ${ }^{13,26,27}$, respectively who found that oral health attitude and behaviour of clinical students is higher than that of preclinical. In contrast, Al-shiekh et al. ${ }^{6}$ found no differences in the oral health attitude and behaviour of clinical students compared with preclinical students in Sudan. This may be attributed to the weak knowledge of students to preventive dentistry and this is reinforced by the fact that the dental students who participated in the study were taught preventive dentistry during year 4 according to the University's curricula and this might have caused a poor effect on their attitude and behaviour.

This study revealed that oral health knowledge, attitude and behaviour improved with increasing academic levels, indicating that there is increase in the dental education experience gained 




(1)

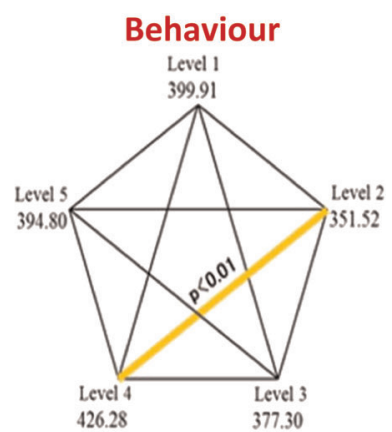

(2)

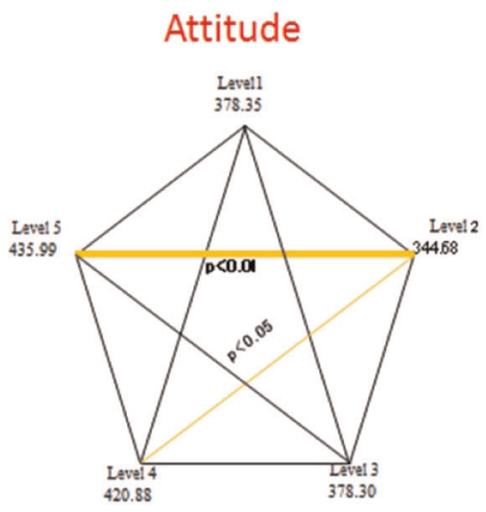

(3)

Fig. 1 A Penta histogram of the knowledge, behaviour and attitude of all academic levels

from basic dental subjects, preventive courses and clinical training. This result is consistent with the results reported in a study comparing HU-DBI questionnaire between Greek and Japan ${ }^{22}$ and other studies in Jordan, ${ }^{18}$ in Nigeria ${ }^{28}$ and in India ${ }^{17}$ as they showed that oral health attitude and behaviour improved by educational levels. By contrast, results reported by Halboub et al. ${ }^{7}$ revealed that oral health attitude and behaviour of dental students in Yemen were not improved with increasing levels of education that means faulty understanding for the acquired knowledge and their translation into negative attitude and behaviour which necessitates critical revision of the curricula.

This study was carried out in only one private dental school and thus it might limit the generalizability of the results all over Egypt. So, more studies are needed in different dental school in Egypt. Using the HU-DBI in this study reported interesting facts regarding differences in oral health attitudes and behaviours between undergraduate dental students. Dental students, as future health professionals, should have a comprehensive dental educational oral health in school programs including self-care regimes and preventive courses starting from the 1st year of dental education.

\section{CONCLUSIONS}

Within the limitations of this study, we conclude the following:

1. The oral health knowledge, attitude and behaviour of preclinical dental students were lower than that of clinical ones.

2. Preclinical students need properly designed oral health educational programs to increase their attitude and behaviour toward oral health.

\section{AUTHOR CONTRIBUTIONS}

A. A. Al-w. contributed to idea of research, questionnaire distribution and collection, interpretation the results, preparation of master table results and writing the paper; F. A. contributed to idea of the research, preparation of master table for the results, interpretation of the results and writing and revising the paper; K. El. M. contributed to idea of the research, interpretation the results and revising the paper; H. S. contributed to data analysis and revising the paper. All authors gave final approval and agree to be accountable for all aspects of the work.

\section{ADDITIONAL INFORMATION}

Competing interests: The authors declare no conflict of interest.

Publisher's note Springer Nature remains neutral with regard to jurisdictional claims in published maps and institutional affiliations.

\section{REFERENCES}

1. Ireland, R. Dictionary of Dentistry-Oxford Reference. http://www.oxfordreference. com/view/10.1093/acref/9780199533015.001.0001/acref-9780199533015 (2010).

2. Gallagher, E. B. \& Moody, P. M. Dentists and the oral health behavior of patients: a sociological perspective. J. Behav. Med. 4(3), 283-295 (1981).

3. Khami, M. R., Virtanen, J. I., Jafarian, M. \& Murtomaa, H. Prevention-oriented practice of Iranian senior dental students. Eur. J. Dent. Educ. 11(1), 48-53 (2007).

4. Sato, M. et al. Effect of dental education on Peruvian dental students' oral healthrelated attitudes and behavior. J. Dent. Educ. 77(9), 1179-1184 (2013).

5. Peker, I. \& Alkurt, M. T. Oral health attitudes and behavior among a group of Turkish dental students. Eur. J. Dent. 3(1), 24-31 https://PMC2647956/ (2009).

6. Al-shiekh, L., Muhammed, M.E., Muhammed, A.E., El-huda, M.A. \& Hashim, N.T. Evaluation of dental students' oral hygiene attitude and behavior using HU-DBI in Sudan. Sci. Postprint.1(2). https://doi.org/10.14340/spp.2015.01A0001 (2015).

7. Halboub, E. S. et al. Self-reported oral health attitudes and behavior of dental and medical students, Yemen. Glob. J. Health Sci. 8(10), 143-150 (2016).

8. Kawamura, M. et al. An exploratory study on cultural variations in oral health attitudes, behaviour and values of freshman (first-year) dental students. Int. Dent. J. 55(4), 205-211 (2005).

9. Komabayashi, T. et al. A comparative study of oral health attitudes and behaviour using the Hiroshima University - Dental Behavioural Inventory (HU-DBI) between dental students in Britain and China. J. Oral. Sci. 47(1), 1-7 (2005).

10. Cortes, F. J., Nevot, C., Ramon, J. M. \& Cuenca, E. The evolution of dental health in dental students at the University of Barcelona. J. Dent. Educ. 66(10), 1203-1208 (2002).

11. Peker, K., Uysal, O. \& Bermek, G. Dental training and changes in oral health attitudes and behaviors in Istanbul dental students. J. Dent. Educ. 74(9), 1017-1023 (2010).

12. Neeraja, R., Kayalvizhi, G. \& Sangeetha, P. Oral health attitudes and behavior among a group of dental students in Bangalore. Eur. J. Dent. 5(4), 163-167 (2011).

13. Yildiz, S. \& Dogan, B. Self reported dental health attitudes and behaviour of dental students in Turkey. Eur. J. Dent. 5(3), 253-259 (2011).

14. Kawamura, M., Kawabata, K., Sasahra, H., Fukuda, S. \& Iwamoto, Y. Dental behavioral science Part IX. Bilinguals' responses to the dental behavioral inventory (HU-DBI) written in English and in Japanese. J Hiroshima Univ Dent Soc. 24, 185-192 (1992).

15. Kawamura, M. et al. Relationship between CPITN and oral health behaviour in Japanese adults. Aust. Dent. J. 38(5), 381-388 (1993).

16. Kawamura, M., Spadafora, A., Kim, K. \& Komabayashi, T. Comparison of United States and Korean dental hygiene students using the Hiroshima university-dental behavioural inventory(HU-DBI). Int. Dent. J. 52(3), 156-162 (2002).

17. Puri, M. S., Puri, N., Singh, K., Kaur, N. \& Kaur, A. Influence of dental education on oral health attitude and behavior of 1 st year dental students through Interns. EC Dent. Sci. 1(2), 225-231 (2015).

18. Al-Omiri, M. K., Barghout, N. H., Shaweesh, A. I. \& Malkawi, Z. Level of education and gender-specific self-reported oral health behavior among dental students. Oral. Health Prev. Dent. 10(1), 29-35 (2012).

19. Al-Wahadni, A. M., Al-Omiri, M. K. \& Kawamura, M. Differences in self-reported oral health behavior between dental students and dental technology/dental hygiene students in Jordan. J. Oral. Sci. 46(3), 191-197 (2004).

20. Rahman, B. \& Al Kawas, S. The relationship between dental health behavior, oral hygiene and gingival status of dental students in the United Arab Emirates. Eur. J. Dent. 7(1), 22-27 (2013).

21. Vangipuram, S., Pallavi, S., Radha, G. \& Rekha, R. Assessment of oral health attitudes and behavior among undergraduate dental students using Hiroshima 
Oral health knowledge, attitude and behaviour of dental students in a... A.A. Al-wesabi et al.

University Dental Behavioral Inventory HU-DBI. J. Indian Assoc. Public Health Dent. 13(1), 52 (2015).

22. Polychronopoulou, A. \& Kawamura, M. Oral self-care behaviours: comparing Greek and Japanese dental students. Eur. J. Dent. Educ. 9(4), 164-170 (2005).

23. Dagli, R. J., Tadakamadla, S., Dhanni, C., Duraiswamy, P. \& Kulkarni, S. Self reported dental health attitude and behavior of dental students in India. J. Oral. Sci. 50(3), 267-272 (2008).

24. Kawamura, M., Iwamoto, Y. \& Wright, F. A. A comparison of self-reported dental health attitudes and behavior between selected Japanese and Australian students. J. Dent. Educ. 61(4), 354-360 (1997).

25. Badovinac, A. et al. Oral health attitudes and behavior of dental students at the University of Zagreb, Croatia. J. Dent. Educ. 77(9), 1171-1178 (2013).

26. Pacauskiene, I. M., Smailiene, D., Siudikienè, J., Savanevskyte, J. \& Nedzelskien, I. Self-reported oral health behavior and attitudes of dental and technology students in Lithuania. Stomatologija 16(2), 65-71 (2014).

27. Ahamed, S. et al. Evaluation of the oral health knowledge, attitude and behavior of the preclinical and clinical dental students. J. Int. Oral. Heal. 7(11), 65-70 (2015).
28. Okoh, M. \& Enabulele, J. Influence of clinical experience on oral health attitude and behaviour of dental students attending a Nigerian university. Odontostomatol Trop. 37(12), 25-31 (2014).

(i) Open Access This article is licensed under a Creative Commons Attribution 4.0 International License, which permits use, sharing, adaptation, distribution and reproduction in any medium or format, as long as you give appropriate credit to the original author(s) and the source, provide a link to the Creative Commons license, and indicate if changes were made. The images or other third party material in this article are included in the article's Creative Commons license, unless indicated otherwise in a credit line to the material. If material is not included in the article's Creative Commons license and your intended use is not permitted by statutory regulation or exceeds the permitted use, you will need to obtain permission directly from the copyright holder. To view a copy of this license, visit http://creativecommons. org/licenses/by/4.0/.

(c) The Author(s) 2019 